\title{
Is the Technology a New Way of Thinking?
}

\section{Abstract}

In his consideration of thought development, Auguste Comte proposed a three-stage model, in which the mechanism of development may lead to new types of thought. So the process that led to a philosophy of science may be repeated to create a new type of thought. The thought development is attributed to a process of accumulation of challenged but unanswered questions, followed by a decline of interest in that type of thinking.

The science stage presented a huge accumulation of achievements, but at the same time it confronts huge challenges. The present work is a theoretical analysis for what is happening because of these challenges. The author believes that the technology may be regarded as a fourth stage for Comte's model. The technology stage corresponds to globalization as a social stage. Technology has its own methodological way. Owing to the connection between the technology and human need, the development of technology follows a Darwinian evolution model. The process of technology selection that leads to development is the user selection, which corresponds to Charles Darwin's natural selection.

Keywords: Philosophy of technology, Threestage model, New scientific spirit, Globalization, Thought evolution, Technology development.

\section{Introduction}

The development of human civilization is associated with the development of knowledge. Auguste Comte traced thought development through time and formulated his law of three stages (Comte, 1855). Comte postulated three theoretical stages of development of thought and society: the theological, the metaphysical, and the positive, which correspond to the fictitious, abstract, and scientific ways of thinking, respectively. Each type has a characteristic logic and methodology.

1. The theological stage tries to attribute natural phenomena to personified deities. Thus, explanations of natural phenomena take the form of stories or legends. This stage may have three subdivisions: animism, polytheism, and monotheism.
2. The metaphysical stage uses a rational explanation style; abstract explanations are developed in this stage.

3. The positive stage tries to discover and explain nature according to science and experimental proofs.

Comte (1855) considered social development in a similar set of three stages as well. In his most important work, Comte "explains why the law of the three stages is stated twice. Properly speaking, the law belongs to dynamic sociology or theory of social progress" (Comte, $2008,4.1)$. Comte identifies a stage of material development corresponding to each social developmental stage:

- The theological stage may also be called the military stage, and the military may be a feature of a primitive society;

- The metaphysical stage corresponds to supremacy of the lawyers and jurists;

- The positive stage is industrial; industry is based on scientific achievements.

Comte, an engineer, was up to date with scientific developments of the Industrial Revolution of the 19th century. Table 1 shows the two sets of developments, that of thought and that of society.

Table 1. Comte's stages

\begin{tabular}{|crr|}
\hline & Thinking stage & Social stage \\
\hline 1. & Theological stage & Military \\
\hline 2. & Metaphysical stage & $\begin{array}{r}\text { Supremacy of the } \\
\text { lawyers and jurists }\end{array}$ \\
\hline 3. & Positive stage & Industrial \\
\hline
\end{tabular}

In the early years of the last century, there were revolutionary achievements in pure theoretical physics (PTP), including the development of the theory of relativity and quantum physics, which made pure physics the main branch of the modern history of physics. The strong agreement between theoretical predictions and experimental investigations led to great support for that branch of knowledge. The unusually large number of achievements in PTP during the first 
three decades of the last century motivated Gaston Bachelard's declaration of his new scientific spirit (Bachelard, 1985) or a new philosophy of science. A new type of physical thought based on probabilities of single particles and the accumulation of new achievements were behind his declaration. However, at that time, there were no recognized serious obstructions confronting quantum physics, one of Kuhn's (1962) scientific revolutions.

The present work is a discussion of a possible new phase of thinking, the fourth stage according to Comte's scale. This work is organized as follows:

- An overview of the mechanisms of thought development.

- A review of the present situation of science research.

- Postulation of a new stage, according to the mechanism of development.

- Investigation of the features of this new stage.

This work is not a philosophical study but a study in philosophy. Thus, the approach will not follow the philosophical argumentation. Instead, an analytical approach for the situation of science and technology is followed.

\section{The flow and obstruction model}

The development of thought can be explained by either dialectical or evolutionary processes. The materialism proposition states that the mere augmentation of a thing or things produces a change in quality and characteristics and, conversely, that a qualitative change

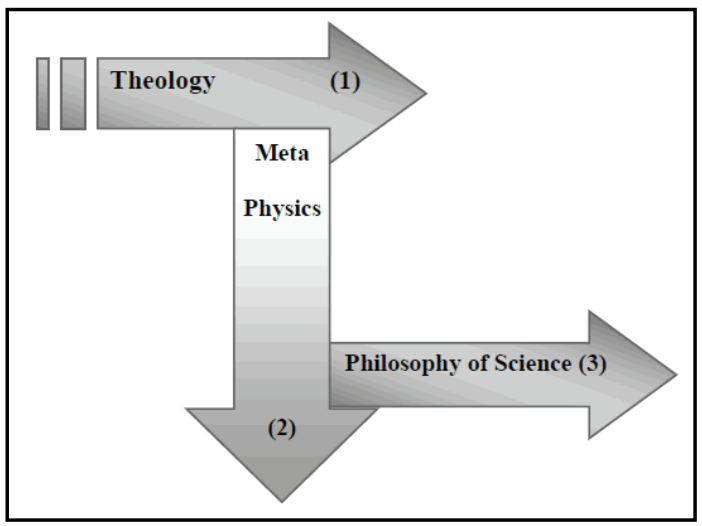

Figure 1. Changing the direction of thought mainstream (as flow) according to Comte's three mentally conceived stages. produces a quantitative one (Thalheimer, 1936). Accordingly, the deflection of thought to a new direction may be considered a historical necessity. This process can also be considered using Toynbee's (1987) challenge and response theory. In this model, new types of thinking are responses to challenges.

The change of thought mainstream is somewhat similar to changes in the direction of flow of water due to an obstruction. In this model, "obstructions" develop from an accumulation of challenging questions or unconvincing answers. To represent how the "mainstream" direction changes, Figure 1 represents the types of thought mainstream with different directions of flow.

However, for Comte, "theology declined as it was challenged by scientific spirit, which fulfilled people's need much more effectively" (Pickering, 1993, p. 633). Theological (fictitious) interests declines in favor of metaphysical (abstract) works, and metaphysical interests decline in favor of scientific thought. The decline and challenges might have led Auguste Comte to his proposal of thought development. The diversion of the mainstream thinking to a new type of thinking appears to occur as a result of two types of accumulations:

1. The accumulation of challenged questions (lack of logic). This accumulation works as an obstruction and forces the mainstream to change direction.

2. The accumulation of potential (achievements) to find a new way of thinking. This accumulation is based on the previous achievements of the blocked thinking and provides the potential for the new direction of flow.

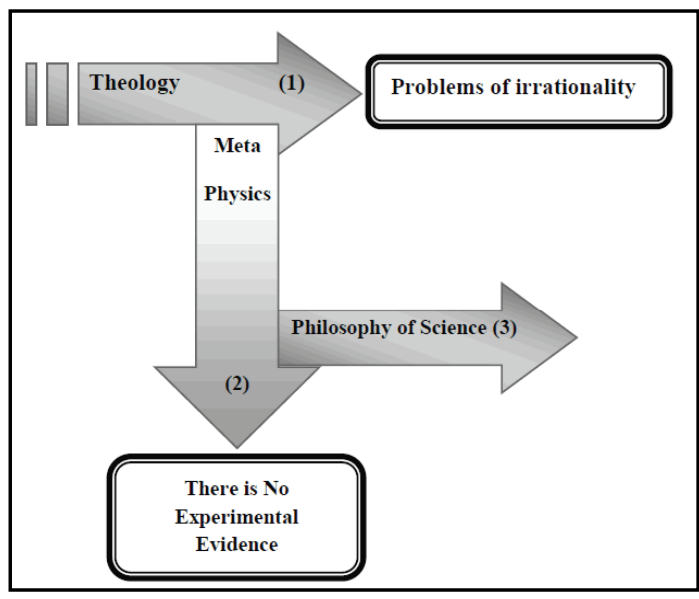

Figure 2. Flow of thought and effect of obstructions. 
Figure 1 shows the diversion of thought flow, and Figure 2 represents the flow of thought and the obstruction effect for the three types of thinking. The process of development looks like a mechanism of flow and obstruction. The new stream due to the obstruction is of the new feature.

\section{Pure research and the accumulations}

In Europe, the remarkable shift toward scientific thought occurred during the scientific revolution in the 16th and 17th centuries (Shapin, 1998). Science started to change the direction of how people understood nature and started to affect religious belief. Shapin and many other historians (e.g., Lindberg, 1987) insisted on "Science as Religion's Handmaid," referring to Comte's second stage (metaphysics). Science as knowledge occupied the place of religion in providing alternative interpretation of the natural phenomena and provides solution for some of life's problems. Science without applications (without technology) does not have that effect on life developments of society. It may affect the understanding of nature and then social beliefs or social thought; that is quite clear in comparison the social effect of both of Darwin's evolution theory and Marconi's radio invention. The first led to a religious shock, whereas the second improved the quality of life.

Like any new belief or thought, science affects society after any scientific revolution. The historical period that most marks the beginning of science's effect on society was the socalled Industrial Revolution (18th and 19th centuries). That revolutionary era led Comte to the concept of industrial society. The adoption of industry for the science achievements and discoveries led to serious influence of science on society.

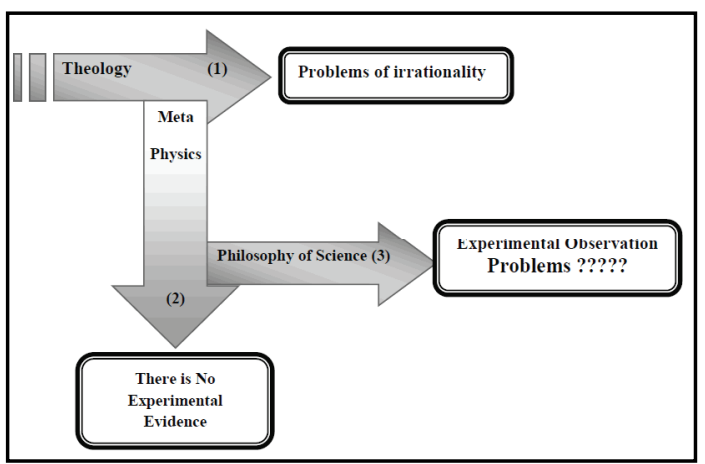

Figure 3. The problems that change thought.
However, during the first half of the 19th century, the scientific environment became more notable and influential than it had been before for many reasons:

- Science was able to explain nature in a more convincing way than either theological or metaphysics theories.

- The benefit, persuasiveness, and applicability of scientific knowledge made scientific studies more favorable and popular than theological or metaphysical studies. Subsequently, most universities turned gradually from theological to scientific studies.

- There were large developments and an accumulation of scientific achievements.

This new type of thought rose as a new challenge to the dominant metaphysical type of thought. It led to slower growth or relative decline in metaphysical (abstract) works and interests compared with the growth of scientific achievements. Then, Positivism became the new direction of thought flow (Figure 2).

Thus, the process of increase and decline may mark an era of a new type of thought. In describing the evolution process, Comte's law identifies only three stages, but these may be followed by many other stages as long as there is accumulation and obstruction.

In conclusion, the advancement and accumulation of scientific achievements led to a new way of thinking (see Figure 3).

\section{New accumulations}

Through pure research, scientific developments led to two types of accumulation:

- The accumulation of a huge number of scientifically proven achievements (scientific fact) that describe nature and can be used for many different applications.

- The accumulation of theoretical works without experimental investigation.

There are many philosophical attempts to classify and define sciences. Within science communities, the definition of pure or basic research is controversial, and it is far from the definition of basic science; there is no unified definition (Calvert \& Martin, 2001). Here, the 
focus is on the epistemological and intentional features of research and the definition from the Organisation for Economic Co-operation and Development (OECD). Basic research "is experimental or theoretical work undertaken primarily to acquire new knowledge of the underlying foundations of phenomena and observable facts, without any particular application or use in view" (OECD, 1994).

These two accumulations are epistemological in nature. The second accumulation is that of theoretical works that are impossible (at least in the present time) to investigate experimentally. For example, most of the theoretical predictions of PTP in the second half of the 20th century, such as string theory (Schroer, 2008; Smolin, 2006; Woit, 2007), black hole theories, and black matter theories, at different levels (microphysics and cosmological physics) faced and are still facing large obstructions to experimental investigations. Theoretical works accumulate and grow rapidly relative to the level of the slow development of technology of the experimental investigations. As in the example of PTP, either the needed technology is too advanced and sophisticated, or the needed technology is beyond the present level of science (e.g., space travels of superluminal velocity).

These problems are not easily overcome and may form knowledge barriers that lead to knowledge boundaries (Sanduk, 2008), as shown in Figure 4 . These boundaries resemble ultimate limits at both the microscopic and cosmological levels. Scientists start to confront the feeling their usual probing investigation may be at an end. In PTP, a huge amount of theoretical work is now carried out without investigations, and great numbers of research articles around the world are in need of experimental evidence. These boundaries are neither metaphysical nor faith based.

Edmund Husserl (1970) predicted a crisis of science in his article, "The crisis of the European Sciences," but his point of view was based on intentional phenomenology. Aldous Huxley mentioned limits on studies in his fifth novel in which he wrote in 1931 that "we can't allow science to undo its own good work. That's why we so carefully limit the scope of its researches" (Huxley, 1998, p. 227). In this sentence, Huxley may mean an imposed restriction on research, which is different from the limits mentioned previously.
However, PTP is a good example for the growth and decay of interest in science. In the first decades of the 20th century the great achievements of PTP made it very popular and garnered a great deal of research interest.

However, PTP's honeymoon did not continue. Its decline began in the second half of the 20th century. This became noticeable during the 1990s, when pure physics research grants began to shrink, as did students' interests. The decline was quite obvious and continues today (Cressey, 2008).

In addition to the two accumulations of epistemological nature, there is a growth of human demand for a better and comfortable life. Scientists distinguish between pure research and applied research. Applied research aims to solve a particular problem related to direct application. With aid of pure research outputs, applied research can find solutions for human demands. Technology tries to fulfill human needs (de Weck, Roos, \& Magee, 2011)

Contemporary technology (like IT, nanotech, genetic engineering ... ) is based on large accumulations of science outputs, which can help in diverse applications and technology. Thus, a large accumulation provides technology with an extremely high potential for rapid growth.

Technology depends on two types of research: basic science studies (which has a high accumulation of achievements) and research \& development $(\mathrm{R} \& \mathrm{D})$, which is adopted and supported by industry, government, and others.

Interest in basic research declines in favor of applied and development research (or R\&D),

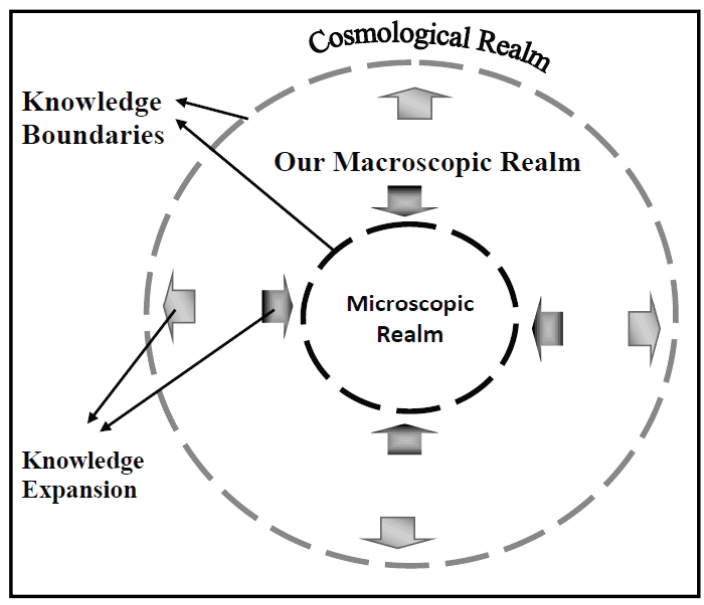

Figure 4. The boundaries of scientific knowledge. 
which is clearly observed in developed countries. Figures $5 \& 6$ show the funding of

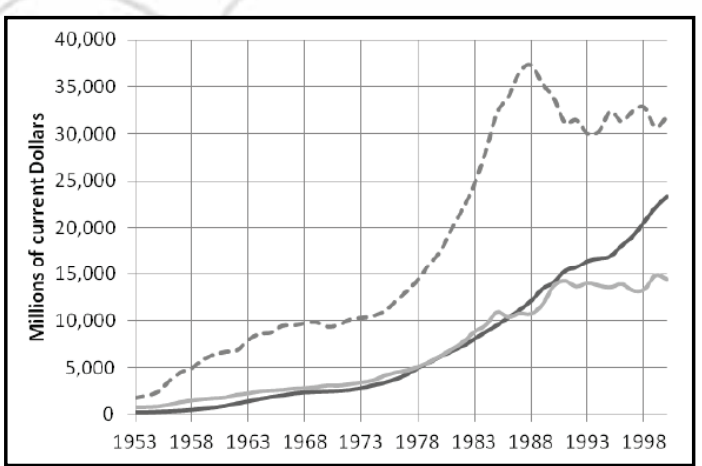

Figure 5. U.S. federal government spending development for the basic, applied and development research (1953-2000) (Science and Engineering, Indicators 2002).

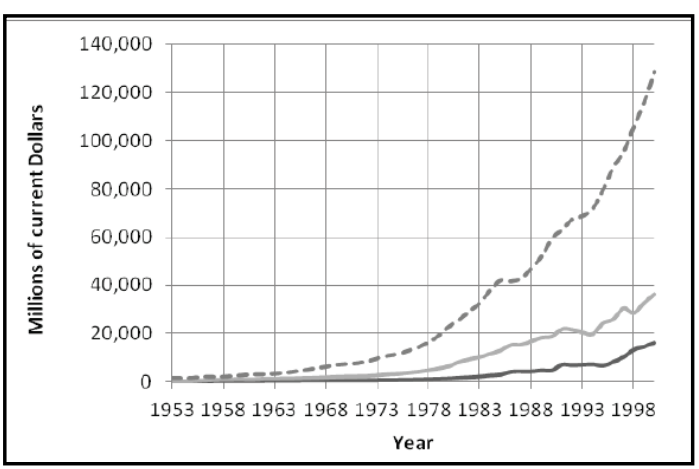

Figure 6. The U.S. industry spending development for basic, applied and development research (1953-2000) (Science and Engineering Indicators, 2002).

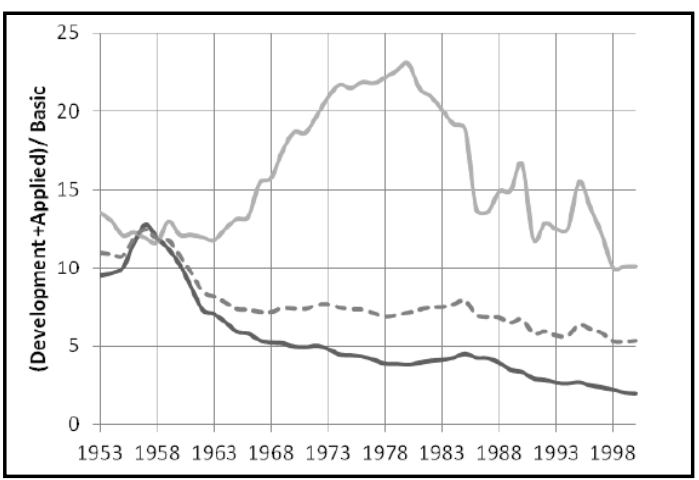

Figure 7. The ratio of U.S. spending on R\&D to spending on basic science for both federal government and industry sectors (1953-2000).

research in the United States during the second half of the last century (the period 1953-2000). Interest in basic research supported by industry declined, compared with research on applications and development. Based on these data, Figure 7 shows the ratio of the funding of development and applied research to the funding of basic research. It is obvious that the federal government, rather than industry, tries to support basic science. However, basic research still earns less support than applied research and development. There is no doubt that the vital role of basic research resulted in the federal government's change in its funding policy after 1958. Nevertheless, the balance remained in favor of applied and development research.

Social interest in science may be reflected by the number of graduate students and by employment opportunities. For example, Figure 8 shows the number of earned bachelor's degrees in the United States in different fields during the period 1993-2007. Growth of student

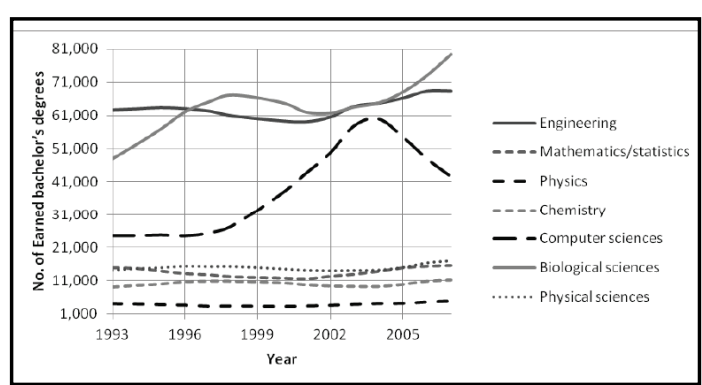

Figure 8. The number of the earned bachelor's degrees in USA for different field at period 1993-2007 (Science and Engineering Indicators, 2010).

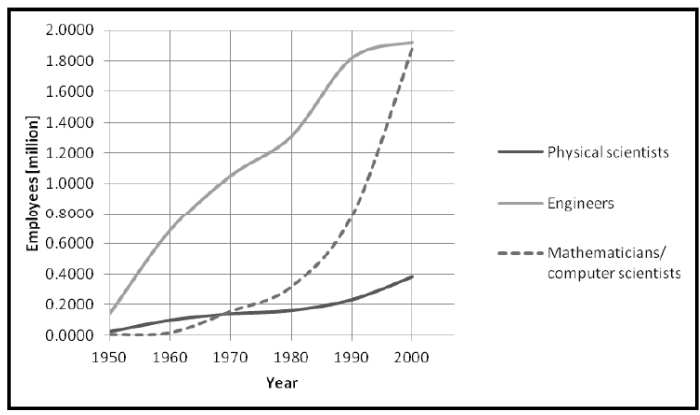

Figure 9. Employees in science and technology in the USA 1950-2000 (Science and Engineering Indicators, 2010).

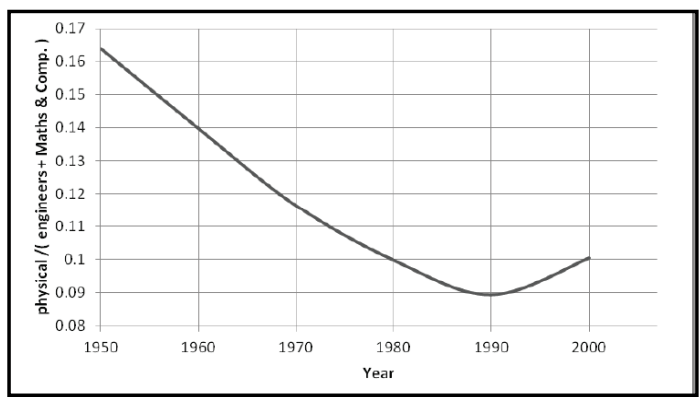

Figure 10. The ratio of physical scientists to engineers, mathematicians and computer scientists. 
interest is observed in applied fields, such as engineering, biological sciences, and computer sciences, whereas no such significant growth is shown in the physical sciences, such as physics, chemistry, and mathematics. Tracing historical employment in science and technology shows a growth in engineering and computational jobs relative to physical science jobs (Figures 8, 9, and 10).

The United Kingdom is a similar case. In a 2008 report titled "Review of UK Physics" (Research Councils UK, 2008), the authors concluded the following:

- "There has been a significant decline in recent years of the number of students taking physics at A level (a stage before university) ...."

- "Physics has a significant impact on the economy and society . . . . Possibly, the most valuable contribution appears to be physics trained graduates, who are highly sought after in many sectors of the economy."

- "The Panel heard from many sources that more needs to be done to encourage university-based physicists to work more closely with industry .... We found that much of the research work in physics that was of direct interest to business was being performed in departments other than physics in the university sector. This has the effect of reducing the number and size of income streams to physics departments ..."

We focused on the PTP as an example. Yet many branches of sciences are reaching their peak of growth now (like genetic researches), but this is just a growth step similar to what it was like for PTP. The decline is a natural phenomenon. The present pure science situation is similar to that of the decline in metaphysics. Science is the third stage in Comte scale; Does the decline in pure science interest lead to a new deviation in the flow of thinking?

\section{Is there a new fourth stage?}

Because there is always a new accumulation and decline, the evolution of thought may lead to many new philosophical phases.

The relationship between science and technology is the relationship between need and knowledge, and historically it is a deep relationship. Following the model of flow and obstruction, a new stream is expected. The previous discussion (the paragraph of New accumulations) shows clearly the real observable growth of applied science. That growth is faster than the growth of basic science, and it is more complicated.

Due to the complicated structure of technology (technology is dependent on scientific facts, engineering, politics, trade, etc.), technology develops rapidly as an exponential trend over time. Figure 11 shows the rapid growth of the technology of global ICT and the retardation of others (old technology, like fixed telephone). Mobile technology looks as of exponential trend.

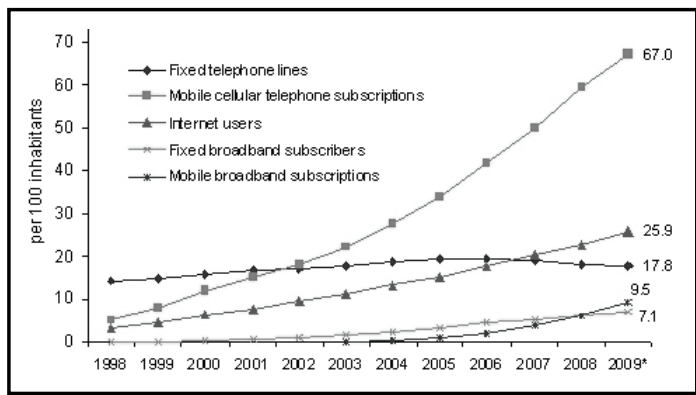

Figure 11. Global ICT developments, 1998 - 2009 (ITU World Telecommunication/ ICT Indicators database, 2009).

The fourth stage is obviously based on science, but it goes beyond science with a more complicated structure. Thus, the next stage is technology (see Figure 12).

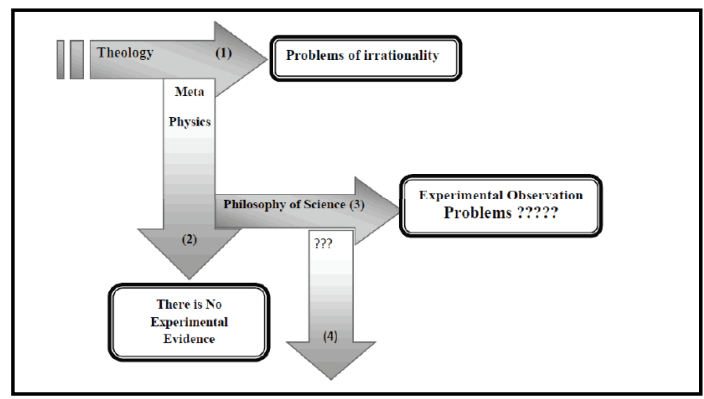

Figure 12. The possible fourth stage.

\section{Philosophy of technology}

In the late 19th and early 20th centuries, John Dewey was optimistic about the role of technology and adopted a pragmatic view (McDermott, 1981).

The intensive interest in this type of thinking started around the middle of the last century, when technological achievements appeared to 
have manifested some serious effects on human society, such as the problems of the World War II, as identified by Martin Heidegger

(Heidegger, 1993). The fast growth of technology and its side effects and misuse led to distinguish it from science. The first clear and focused report on the serious role of technology is the "Mount Carmel Declaration" of 1974 (50 Technion, 1974). The declaration insisted on technology without science. It is the first report written and signed by scientists. The declaration warns of the misuse of technology and puts it in the ranks of the threat of human welfare and survival.

Interest in technological thinking was adopted academically, as many philosophers now are considered technology philosophers. Most of the works of these philosophers concern the social or humanitarian effects and history of technology. However, technology is more complicated than these limited considerations. The new generation of engineers and technologists are interested in the philosophical background and the social impact of their works or innovations. Some of them cannot distinguish between the logic of science and the methodology of engineering and technology.

However, due to new applications or science products, a new type of methodology has been effectively implemented since the end of the last century (Sanduk, 2003). Technology is unlike science; it starts with applicable invention. Necessity drives invention, as the age-old maxim states. This drive has no full acceptance by the technology historian (The EMELSONMIT Program, 2004). In the present work, the drive of invention is regarded as a type of need (to make life easy, to address physiological needs, etc.). Proving a new idea depends on scientific laws, engineering, then industry, trade, politics, sociology, and more, for production, marketing, and so on. Just as science has its methodology, so technology has its own working logic (Figure 13). In his book Globalization and Technology, Rajneesh Narula presented a diagram relating $R \& D$ to technology and science (Narula, 2003, p. 3).

A distinct type of thinking has been initiated, apart from the philosophy of science. The new type has multidisciplinary features. Although science is characterized by a single type of research, pure research, the R\&D of technology includes the following:
- Applied Research

- Product Research

- Manufacturing Research

- Materials Research

- Market Research

- Operations Research.

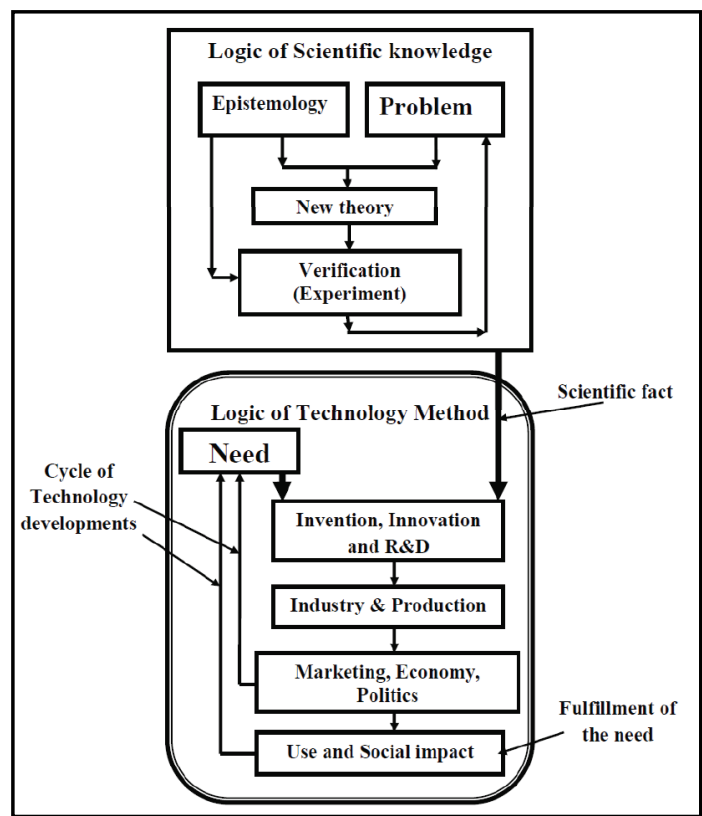

Figure 13. The logic of scientific knowledge and technological methodology.

The technological era is the era of disciplinary mixtures - multidisciplinary or interdisciplinary. It is not a time of separated or isolated sciences.

\section{The development of technology}

Technology has its method of work. It is of a circular nature (Figure 13). Modifications or improvements are expected, and technology advancements occur over time for many different reasons. However, in all cases, the aim of modification is to achieve the fulfilment of need; the best technology is that which best meets the need. Therefore, there are many generations of each type of technological invention (e.g., television, computer, pen). The age of each generation depends on the quality of its performance, the social impact, ethics, market conditions, and so on. The selection of the technology invention in this case is a social selection.

On the other hand, some technologies became obsolete (see Figure 11), and these 


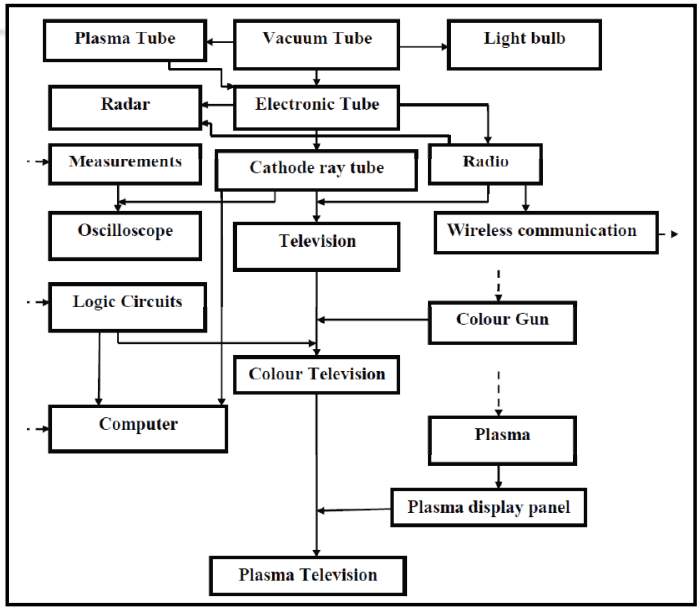

Figure 14. A branch of the vacuum tube family that includes the evolution of the television (Sanduk, 2003).

technologies disappear gradually (or become extinct). Thus, technology development has features that resemble Darwinian evolution. The technology in each step of development will be accepted if it meets the need of that development, as in Herbert Spencer's phrase "survival of the fittest" (Peel, 1972). The process of technology selection that leads to development is the social (user) selection, which corresponds to Charles Darwin's natural selection.

Scientific development occurs through a revolutionary process, according to Kuhn (1962), whereas technological development takes place through a Darwinian type of evolution. The appearance of a new technological invention resembles an evolutionary jump. With different and multiple uses, it will be circulated in many different developmental ways. Many different generations will branch off from that "grandfather." Figure 14 shows a branch of vacuum tube family and the evolution of the television. It is quite clear that the old members of the family are extinct, while the younger generation continues to develop.

\section{Globalization}

Our present societies are not industrial societies; they are more complicated. Technology today is structured in many ways, including

Table 2. The modified model of stages

\begin{tabular}{|ccr|}
\hline & Thinking stage & Social stage \\
\hline 1. & Theological stage & Military \\
\hline 2. & Metaphysical stage & $\begin{array}{r}\text { Supremacy of the } \\
\text { lawyers and jurists }\end{array}$ \\
\hline 3. & Positive stage & Industrial \\
\hline 4. & Technology stage & Globalization \\
\hline
\end{tabular}

industry, economy, politics, and others. The rapid advance of technology creates many types of instabilities (social, personal, global, etc.). The world has become smaller, and any event will receive a rapid response. In 1998, Longworth wrote of the shrinking of the world, "With computer and satellite, currency and stoke traders can do business virtually anywhere at any hour of the day" (Longworth, 1998, as cited in Ramos, 2003, p. 24). Not only have distances decreased but time has shortened as well. In Globalization and Technology, the author examines the interdependence of globalization and technology at two levels, the interdependence between locations, and between corporate entities (Narula, 2003). Humanity looks forward to globalization.

Pascal Lamy of the World Trade Organisation (WTO) defines the globalization as "a historical stage of accelerated expansion of market capitalism, like the one experienced in the 19th century with the industrial revolution. It is a fundamental transformation in societies because of the recent technological revolution which has led to a recombining of the economic and social forces on a new territorial dimension" (Lamy, 2006). This definition suggests that the technology stage corresponds to globalization. Table 2 shows a modified model of Comte's stages. There is no technology without globalization and no globalization without technology; both grow interactively at the same time.

The comparison between Comte's model as shown in Table 1 and the modified model (Table 2) reflects the continuous developments in the thought and society.

\section{Conclusions}

The previous discussion shows a decline in interest in pure science and a growth in interest in applied science and technology interests.

Regarding Comte's model, we may reach to the following conclusions:

- Technology can be regarded as a fourth stage for a modified Comte's model, following the positive stage.

- The technology stage corresponds to globalization as a social stage.

Thus, the technology has its own way of work and development. Technology methodology is quite different from the logic of science. 
Owing to the connection between the technology and human need, the development of technology follows a Darwinian evolution model. The process of technology selection that leads to development is the social (user) selection, which corresponds to Charles Darwin's natural selection.

\section{Acknowledgment}

The author would like to thank Prof. D. Brandon of Technion-Israel Institute of Technology for supplying a copy of the original document of The Mount Carmel Declaration; thanks also for the National Science Foundation, Division of Science Resources Statistics for their advice on collecting the statistical data.

\section{References}

Bachelard, G. (1985). The new scientific spirit (A. Goldhammer, Trans.) Boston: Beacon Press.

Calvert, J., \& Martin, B. (2001) Changing conceptions of basic research? Background Document for the Workshop on Policy Relevance and Measurement of Basic Research, Oslo 29-30 October 2001. www.oecd.org/dataoecd/39/0/2674369.pdf (Accessed 13 October 2011)

Comte, A. (1855/2003). The positive philosophy of Auguste Comte. (H. Martineau, Trans.). Vol. I, p. 1. Kessinger Publishing.

Comte, Auguste. (2008). In (E. N. Zalta, Ed.), Stanford encyclopaedia of philosophy. First published Wed Oct 1, 2008; substantive revision Thu Jun 2, 2011. http://plato.stanford.edu/entries/comte/ (Accessed 2 June 2011)

Cressey, D. (2008). Government was warned of physics crisis. Nature. 16 January 2008.

de Weck, O. L., Roos, D., \& Magee, C. L. (2011), Engineering systems: Meeting human needs in a complex technological world. Cambridge, MA: MIT Press.

The EMELSON-MIT Program (2004). Historical perspectives on invention \& creativity, School of Engineering, Massachusetts Institute of Technology, 15. http://web.mit.edu/invent/n-pressreleases/downloads/history.pdf. (Accessed 30 September 2011)

Heidegger, M. (1993). The question concerning technology (D. Krell, Ed.). (p. 321). New York: HarperCollins Publishers.

Husserl, E. (1970). The crisis of European sciences and transcendental phenomenology; An introduction to phenomenological philosophy (D. Carr, Trans.). Evanston: Northwestern University Press.

Huxley, A. (1998) Brave new world. New York: Harper Perennial Modern Classics, Ch.17.

ITU World Telecommunication/ ICT Indicators database (2009), http://www.ispreview.co.uk/story/2009/10/08/global-mobile-broadband-subscriptions-to-top-600million.html (Accessed 22 October 2011)

Kuhn, T. (1962). The structure of scientific revolutions. Chicago: The University of Chicago Press.

Lamy, P. (2006). Humanising globalization. Geneva, Switzerland: The WTO; [updated 2006 Jan 30; cited 2006 June 1]. Retrieved September 10, 2011, from http://www.wto.org/english/news_e/sppl_e/sppl16_e.htm.

Lindberg, D., (1987). Science as handmaiden: Roger Bacon and the Patristic tradition. Isis, 78(4), 518-26.

McDermott, J. J. (1981). The philosophy of John Dewey. Chicago: University of Chicago Press.

Narula, R. (2003). Globalization and technology. New York: John Wiley and Sons Ltd.

Organization for Economic Co-operation and Development [OECD]. (1994). The measurement of scientific and technical activities: Proposed standard practice for surveys of research and experimental development Paris: OECD (p. 68).

Peel, J. D. Y. (Ed). (1972). Herbert Spencer: On social evolution. Chicago: The University of Chicago Press.

Pickering, M. (1993). Auguste Comte: An intellectual biography, Volume 1. Cambridge, England: Cambridge University Press, p. 633. 
Ramos, C. (2003). Globalization and Technology. Manila: Rex Bookstore, Inc., p. 24.

Research Councils UK (2008). Review of UK physics, panel. Chaired by Professor Bill Wakeham, Swindon.

Sanduk, M. I. (2003). Philosophy of technology, Philosophica, 1 (V), pp. 11-20.

Sanduk, M. I. (2008). Physics limitations and the philosophy of technology, Workshop on Philosophy \& Engineering, WPE2008, The Royal Academy of Engineering London, November 10-12 2008. Retrieved October 13, 2011, from www.raeng.org.uk/societygov/philosophyofeng/pdf/ abstract_papers.pdf

Schroer, B. (2008). String theory the crisis in particle physics and the ascent of metaphoric arguments. IJMPD 17, 2373-2431.

Shapin, S. (1998), The scientific revolution. Chicago: The University of Chicago Press.

Science and Engineering, Indicators (2002). Volume 2- Appendix tables, Chapter 4, Retrieved October 16, 2011, from http://www.nsf.gov/statistics/seind02/pdf_v2.htm

Science and Engineering Indicators: 2010 (2010), Appendix tables, Table 2-12, Retrieved October 16, 2011, from http://www.nsf.gov/statistics/seind10/appendix.htm

Smolin, L. (2006). The trouble with physics: The rise of string theory, the fall of a science, and what comes next. Boston: Houghton Mifflin Harcourt. Retrieved September 2, 2011, from www.rcuk.ac.uk/documents/reviews/physics/review.pdf

50 Technion Wunsch International Symposium Ethics in an age of pervasive technology, (1974). The Mount Carmel declaration on technology and moral responsibility, Technion - Israel Institute of Technology, Haifa.

Thalheimer, A. (1936). Introduction to historical materialism-The Marxist view. New York: Covici Friede.

Toynbee, A. (1987). A study of history, Vol. 1: Abridgement of Volumes I-VI. New York: Oxford University Press.

Woit, P. (2007). String theory and the crisis in particle physics, Gulbenkian Foundation Conference on Is Science Near Its Limits? 25-26.

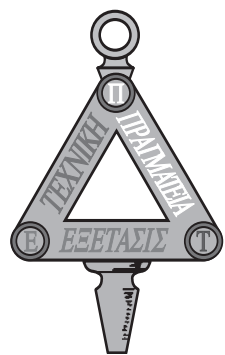

